\title{
Heat treatment as a route to tailor the yield-damping properties in A356 alloys
}

\author{
V.H. Carneiro ${ }^{\mathrm{a}, *}$, H. Puga ${ }^{\mathrm{b}}$, J. Meireles ${ }^{\mathrm{a}}$ \\ ${ }^{\text {a } M E t R i C S ~-~ M e c h a n i c a l ~ E n g i n e e r i n g ~ a n d ~ R e s o u r c e ~ S u s t a i n a b i l i t y ~ C e n t e r, ~ P o r t u g a l ~}$ \\ ${ }^{b}$ CMEMS - Centre for Micro-Electro Mechanical Systems, Portugal
}

\section{A R T I C L E I N F O}

\section{Keywords:}

Casting

Yield strength

Damping ratio

Tailoring

Ageing

\begin{abstract}
A B S T R A C T
A356 is a common industrial alloy due to its relatively good mechanical properties, reduced weight and capability be casted into complex structures. However, in order to display good static mechanical properties (e.g. elevated yield strength) it must be heat treated (usually T6), therefore, compromising its dynamic properties (e.g. damping ratio). This study analyses the role of such heat treatments in the overall microstructure of A356 poured in ceramic block, associating the morphology transformations with the internal mechanisms that enhance yield strength and reduce damping. It is suggested that these variables display an inverse proportionality and a linear model is determined for the design of alloys with tailored yield/damping by the use of different artificial ageing times.
\end{abstract}

\section{Introduction}

Al-7Si-0.3Mg, typically referred as A356, is a classic gravity casting hypoeutectic aluminum alloy. It is usually employed in transportation industries [1] (e.g. automotive, railway and aerospace) for its capability to be heat treated, casted in ceramic block to produce thin walled/ complex geometries [2] and overall specific mechanical properties. However, in its as-cast condition, this alloy is characterized by poor mechanical properties (e.g. low yield/UTS strength and extension) and, therefore, must be heat treated [3] (generally by T6, i.e. solution and quenching followed by artificial ageing).

As this alloy comprises a good part of the overall casted products using bulk [3-7] or composite [8-11] forms, there is a continuous research dedicated to its development and characterization. There has been significant research concerning the A356 $\alpha$-Al primary dendrites $[1,2,12,13]$, eutectic Si [14-17], main secondary phases $\left(\beta-\mathrm{Al}_{5} \mathrm{Fe}_{2} \mathrm{Si}\right.$, and $\pi-\mathrm{Al}_{8} \mathrm{FeMg}_{3} \mathrm{Si}_{6}$ ) [18-21] and heat treatments, such as solution $[17,22,23]$ and ageing [24-28]. Additionally, there are numerous studies concerning the effects of melt treatment by chemical or physical processes at a microstructural level. Most chemical processes are based on common grain refinement using $\mathrm{TiB}$ and modification with $\mathrm{Sr}$ [29-31] master alloys, or more expensive combined treatment by Sc $[32,33]$. Recently, physical processes based on ultrasonic vibration have been employed to promote the referred refinement and modification of the matrix morphology $[4,34,35]$.

Several studies have also been published to characterize the influence of the referred processing parameters in the overall mechanical properties of this alloy [36-38]. Fundamentally, there is a strong emphasis on its load bearing capability under quasi-staticloading, either by simple hardness testing $[33,39,40]$ of the casted alloys and/or posterior tensile testing [41-43]. Recent studies show a concern on the damping properties (mainly using DMA) of this alloy $[1,44]$. Given the importance of this characteristic in the reduction of noise/vibration and its implication in practical problems, such as high resonance response, vibration fatigue and comfort issues on the industrial application of A356 alloys, there seems to still be a lack on data on this matter.

Even though, it is also known that there is a general inverse proportionality between static and dynamic (e.g. vibration damping) mechanical properties $[1,44]$ this correlation has not been directly studied in this alloy. From a technological designer point-of-view, this study intends to relate the dependence of static and damping properties of ceramic block poured A356 alloys and use the ageing heat treatment as a route to tailor specific damping ratios and/or yield strengths for specific applications.

\section{Methodology}

\subsection{Alloy casting, heat treatment and sample production}

A356 alloy study was received in the form of $12.5 \mathrm{~kg}$ ingots with the chemical composition shown in Table 1 . Melting of $0.3 \mathrm{~kg}$ of alloy was

\footnotetext{
* Correspondence to: University of Minho, Campus of Azurém, 4800-058 Guimarães, Portugal.

E-mail address: d6705@dem.uminho.pt (V.H. Carneiro).
} 
Table 1

Aluminum alloy chemical composition.

\begin{tabular}{lllllllllll}
\hline \multirow{2}{*}{ Alloy } & \multicolumn{7}{l}{ Chemical composition (\%wt) } \\
\cline { 2 - 9 } & $\mathrm{Si}$ & $\mathrm{Mg}$ & $\mathrm{Fe}$ & $\mathrm{Ti}$ & $\mathrm{Cu}$ & $\mathrm{Mn}$ & $\mathrm{Zn}$ & Res. & $\mathrm{Al}$ \\
\hline $\mathrm{A} 356$ & 7.44 & 0.30 & 0.13 & 0.11 & 0.07 & 0.07 & 0.05 & 0.12 & $\mathrm{Bal}$ \\
\hline
\end{tabular}

carried out in an electrical resistance furnace and maintained in a $\mathrm{SiC}$ crucible at $720^{\circ} \mathrm{C}$ during $30 \mathrm{~min}$ for homogenization. Master alloys of grain refiner $(0.3 \% w t-\mathrm{AlTiB})$ and eutectic Si modifier $(0.02 \% \mathrm{wt}$ $\mathrm{Al}_{10} \mathrm{Sr}$ ) were added and the melt was kept isothermic for $20 \mathrm{~min}$, being stirred every $5 \mathrm{~min}$ to prevent particle sedimentation (a total of 5 stirring routines). It is known that the addition of eutectic Si modifier generates an increase in porosity due to the decrease in superficial tension $[45,46]$. Thus, the regular degassing process was inverted being performed after the addition of the master alloy in the melt. The alloy cooled down being degassed for $5 \mathrm{~min}$ at $710 \pm 5{ }^{\circ} \mathrm{C}$ with Argon, until a pouring temperature of $702 \pm 3{ }^{\circ} \mathrm{C}$ was reached. The melt was poured into pre-heated $\left(230 \pm 2{ }^{\circ} \mathrm{C}\right)$ ceramic blocks with six rectangular openings with the dimensions of $25 \times 4 \times 140 \mathrm{~mm}$, corresponding to the primitive samples to be tested. A total of ten castings were performed to obtain total of sixty samples for optical microscopy, hardness characterization, vibration analysis and tensile testing.

From the referred samples, ten were kept as as-cast reference with the objective of determining the properties of the casted alloy. The remaining specimens were subjected to a solution heat treatment $\left(540{ }^{\circ} \mathrm{C}\right.$ for $480 \mathrm{~min}$ ) and quenched in mild water, in which ten solution treated samples where kept to determine solution sample properties. Finally, forty solution treated samples were subjected to artificial ageing, being maintained at $160^{\circ} \mathrm{C}$ for $8,64,256$ and $512 \mathrm{~min}$. The final artificial ageing time was defined as the peak-age, given that a time of 480-600 [min] is recommended to avoid over-ageing effect on the mechanical properties $[23,47]$. From the tip of each sample, a $5 \mathrm{~mm}$ thick specimen was extracted for microstructural analysis and hardness testing. Samples where afterwards machined to the dimension and shape that is defined for cantilever vibration analysis. Finally, the samples were machined by wire erosion into a dogbone shape for tensile testing.

\subsection{Microstructural characterization and hardness testing}

Optical microscopy (Leica DM2500M) was used to evaluate the microstructural characteristics and morphology of the samples. ImageProPlus software was used to quantify the average size (D - Eq. (1)) and roundness $\left(\mathrm{R}_{\mathrm{n}}-\right.$ Eq. (2)) of the $\alpha$-Al grain and eutectic Si particles, based on their area (A) and perimeter (P). Measurements were carried out according to ASTM E112 Standard and 50 measurements per optical field $(100 \times)$ were performed on 5 different fields.

$D=2 \sqrt{A / \pi}$

$R_{n}=4 \pi A / P^{2}$

Vickers hardness tests were performed using a Shimadzu HMV-2. The indentations were performed on polished specimens with a diamond square-based pyramid under a load of $1 \mathrm{Kgf}$ for $15 \mathrm{~s}$. The measurements were repeated 10 times from which the mean value and standard deviation were calculated.

\subsection{Vibration analysis - determination of damping ratios}

Machined rectangular samples $(23 \pm 0.05 \times 3 \pm 0.05 \times 140 \mathrm{~mm}-$ Fig. 1(a)) were fixed on a cantilever configuration using a vise, maintaining and overall cantilever length of $120 \pm 0.05 \mathrm{~mm}$. An impact hammer (PCB 086) was assembled on a rig composed by a rigid structure that allows the rotation while a pre-tensioned ribbon assures

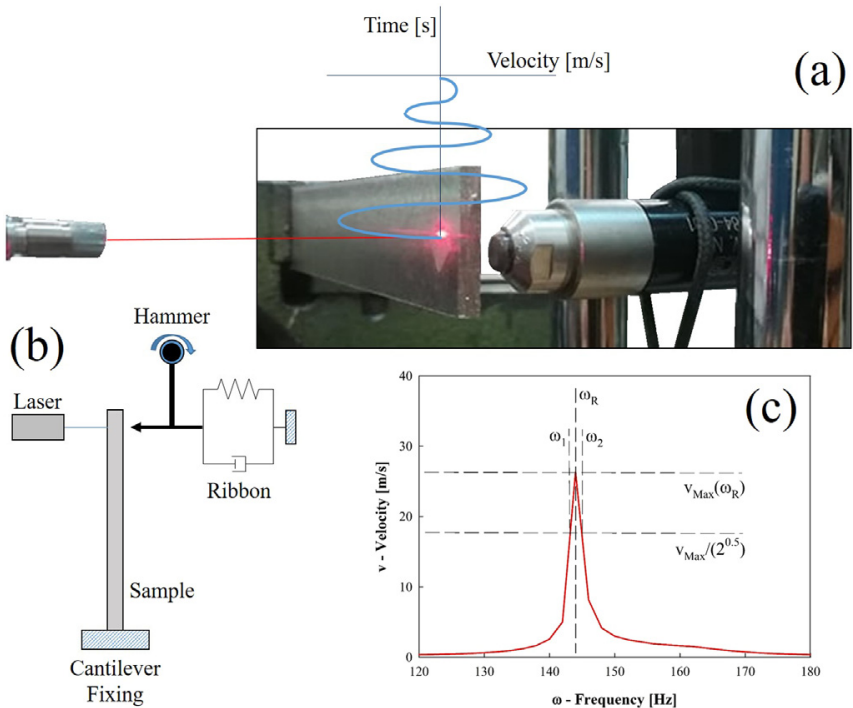

Fig. 1. Vibration analysis: (a) experimental apparatus; (b) schematic representation and (c) half-power bandwidth method for damping ratio determination.

that only one impact $(8.5 \pm 0.15 \mathrm{~N})$ is performed (Fig. 1(b)). A LMS Scadas Mobile spectral analyzer was used to correlate the input excitation data with the velocities captured by the laser (Polytec OFV-512 Fiber Vibrometer). The corresponding frequency response function (FRF) (Fig. 1(c)) was calculated, from which the damping ratios were determined by the half-power bandwidth method from first eigenfrequency response using Eq. (3).

$\zeta=\frac{\omega_{2}-\omega_{1}}{2 \omega_{R}}$

\subsection{Tensile testing - determination of yield strength}

Specimens previously subjected to vibration analysis, had the lateral walls wire eroded to assume a dogbone shape (Fig. 2(a) - Type B1 specimen). Tensile testing was then performed recurring to an INSTRON 8874 universal testing equipment (Fig. 2(b)) according to ISO 6892-1. The samples were tensioned in deformation control with a strain rate of $0.025 / \mathrm{min}$ and the test was stopped when an instant load decrease of $60 \%$ was monitored, meaning that the samples have fractured (Fig. 2(c)). Instant values of load and strain (recurring to a mechanical strain-gauge - Fig. 2(b)) were monitored to determine the yield strength by $0.2 \%$ permanent strain method.
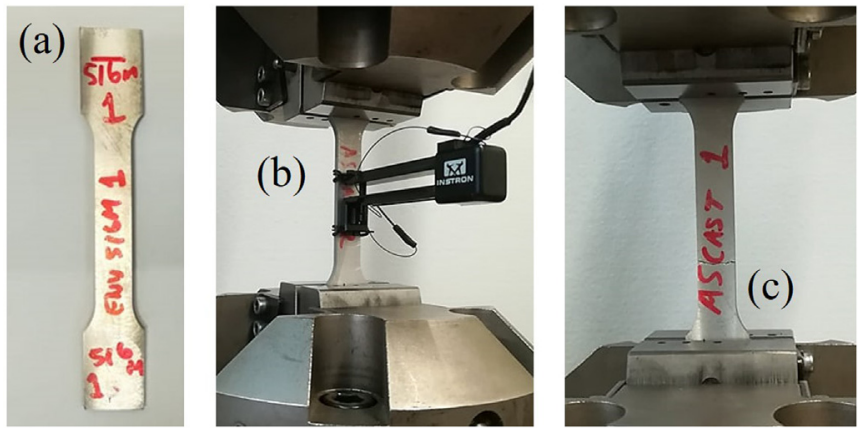

Fig. 2. Tensile testing: (a) initial; (b) during test and (c) fractured samples. 

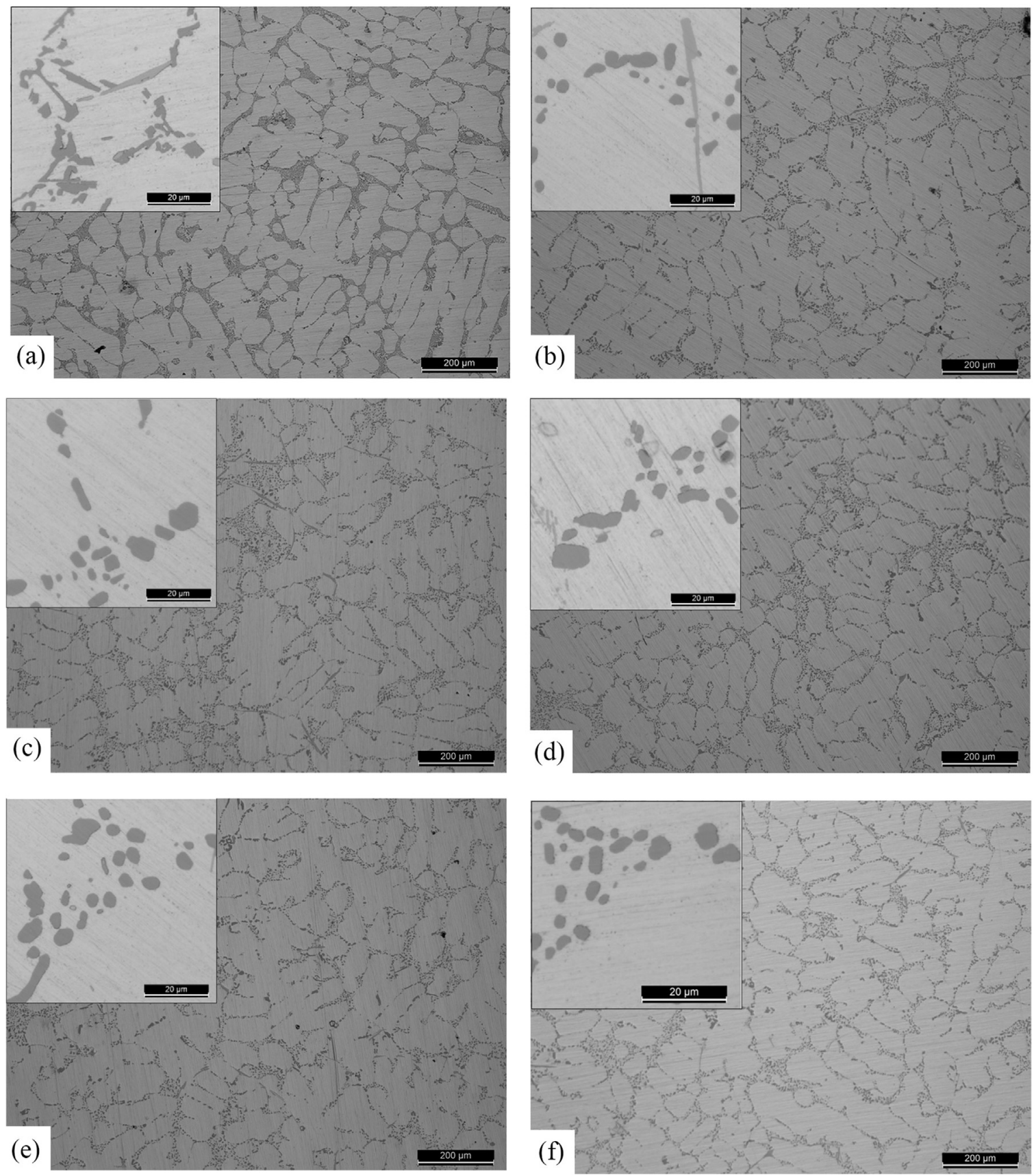

Fig. 3. Microstructural optical microscopies of the (a) as-cast, (b) solution and (c) $8 \mathrm{~min}$, (d) $64 \mathrm{~min}$, (e) 256 min and (f) 512 min artificially aged samples.

\section{Results and discussion}

\subsection{Microstructural characterization and hardness testing}

Fig. 3 presents the microstructures of the produced as-cast (Fig. 3(a)), solution treated (Fig. 3(b)) and artificially aged for $8 \mathrm{~min}$ (Fig. 3(c)), $64 \mathrm{~min}$ (Fig. 3(d)), $256 \mathrm{~min}$ (Fig. 3(e)) and $512 \mathrm{~min}$ (Fig. 3(f)) samples.

The samples in Fig. 3 show a characteristic refinement of the $\alpha-\mathrm{Al}$ grain resultant from the promoted nucleation by AlTiB master alloys. Furthermore, the results in Fig. 4 display an average $\alpha$-Al grain diameter of $80 \mu \mathrm{m}$ that, as expected, does not change significantly with the subsequent solution and ageing treatments. According to these results, although some dendrites may be observed, the high and constant relative roundness of the samples further validate the effectiveness of the performed chemical refinement.
Observing Fig. 3(a), it may be stated that the addition of $\mathrm{Al}_{10} \mathrm{Sr}$ was able to modify the eutectic $\mathrm{Si}$, as it presents a fibrous/coral-shape [31] and no flake-like morphologies may be found. Even though this modification may promote eutectic undercooling [48] and increases the probability of hydrogen entrapment (especially for low cooling rates in ceramic block castings), it is apparent that the inversion of Argon degassing is able to contradict this tendency as no significant porosity is observed in all samples (Fig. 3).

Fig. 5 shows the eutectic Si diameter and roundness evolution in ascast and heat treated samples. As-cast samples (Fig. 3(a)) show smaller modified eutectic Si diameters $(2.8 \mu \mathrm{m})$, however, these particles are more angular and show lower roundness (0.4). It is shown that the solution treatment is able to successfully agglomerate the eutectic $\mathrm{Si}$ particles due to Si self-diffusion and inter-diffusion at the Si-Al interface according to an Ostwald mechanism [22]. This promotes an elevation in the overall Si diameter (from 3.9 to $4.4 \mu \mathrm{m}$ ) that is maintained during 


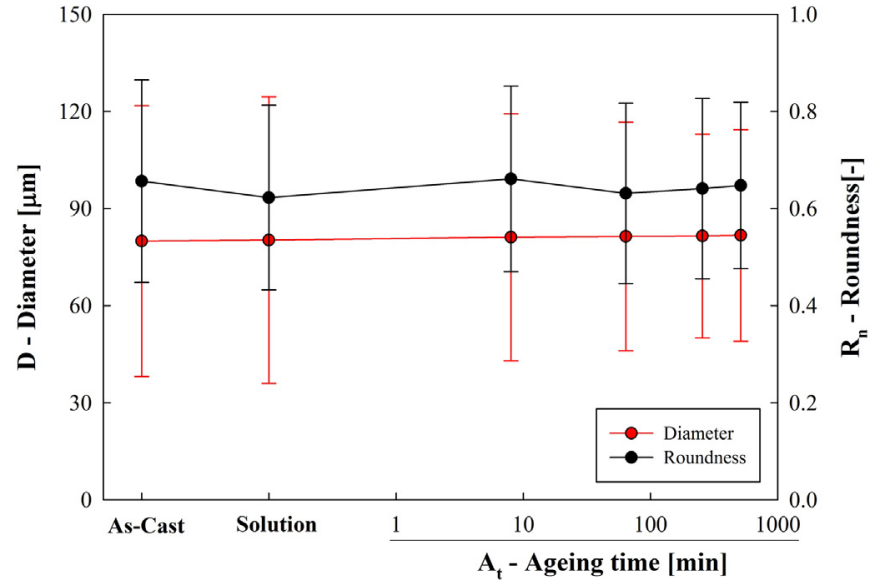

Fig. 4. Average $\alpha$-Al grain diameter and roundness for different heat treatments.

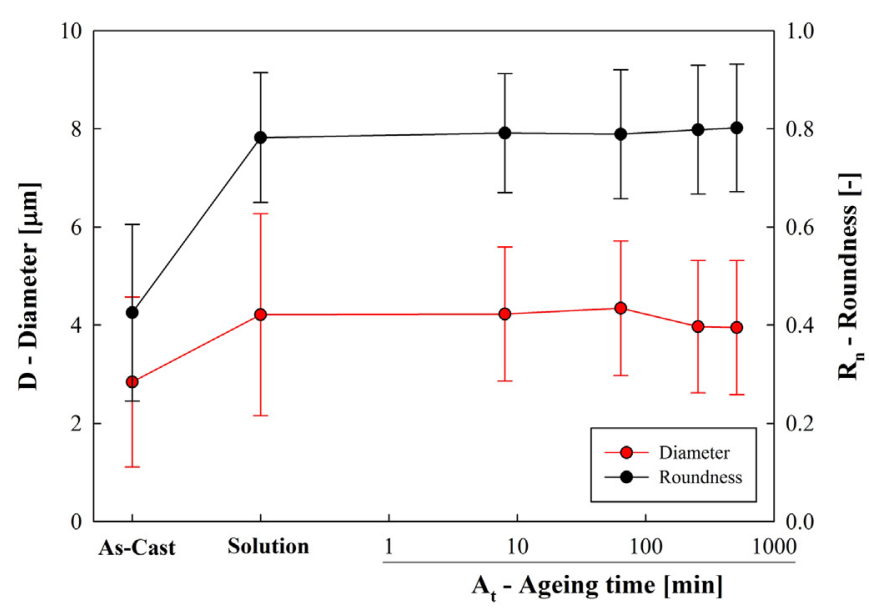

Fig. 5. Average eutetic Si diameter and roundness for different heat treatments.

the ageing treatment. Additionally, there is an increase in particle roundness due to thermally activated Si spheroidization (from 0.4 to 0.8 ) $[12,14]$, that are similar to the values reported in [22]. Overall, it may be also observed that the solution treatment time/temperature is appropriate due to the absence of undissolved $\mathrm{Mg}_{2} \mathrm{Si}$ in the heat treated samples.

According to Figs. 3 and 6 it may be observed that the main secondary phases are needle/platelet-shaped $\beta-\mathrm{Al}_{5} \mathrm{Fe}_{2} \mathrm{Si}$ and script-shaped $\pi-\mathrm{Al}_{8} \mathrm{FeMg}_{3} \mathrm{Si}_{6}$. The precipitation of the latter is further promoted by to the low solid solubility of Fe [18] in as-cast samples and the presence of Mg. Although the subsequent heat treatments do not significantly change the basic Fe intermetallic compounds [18], the solution treatment is able to promote a $\pi-\beta$ transformation during solution $[49,50]$ (Fig. 6). This transformation and the dissolution of $\mathrm{Mg}_{2} \mathrm{Si}$ (Fig. 6) generates a migration of $\mathrm{Mg}$ and $\mathrm{Si}$ atoms to the $\alpha$-Al. Such process allows the solution hardening that is observed in the experimental solution treated results from Fig. 7 .

During the ageing treatment, the supersaturated $\alpha$-Al $\left(\alpha_{S S}\right)$ has its solute $\mathrm{Mg}$ and $\mathrm{Si}$ atoms clustered and precipitated (Eq. (4)) in GuinierPreston (GP $-\mathrm{Mg}_{2} \mathrm{Si}_{3} \mathrm{Al}_{6}$ ) zones along the $<100>$ direction. These primordial precipitates decompose into nano-sized coherent Widmanstätten needle-shaped $\beta$ " $\left(\mathrm{Mg}_{5} \mathrm{Si}_{6}\right)$ and semi-coherent rod-like $\beta$, $\left(\mathrm{Mg}_{1.8} \mathrm{Si}\right)$ metastable strengthening phases [47]. Such precipitates are nucleated in the $<100>$ direction, preferably in dislocation locations. Finally, a dissolved rod/plate-shape equilibrium $\beta\left(\mathrm{Mg}_{2} \mathrm{Si}\right)$ FCC phase is precipitated due to minor atomic rearrangement in the matrix [28].
$\alpha_{S S} \rightarrow G P$ zones $\rightarrow \beta^{\prime \prime} \rightarrow \beta^{\prime} \rightarrow \beta\left(M g_{2} S i\right)$

By the clustering of solute atoms in GP zones and the precipitation of $\beta$ " the overall initial precipitates are shearable and their growth promotes an elevation in hardness [25]. When peak-age is reached, the nucleation and growth of $\beta$ " is superseded by the precipitation and coarsening of non-shearable $\beta^{\prime}$ and $\beta\left(\mathrm{Mg}_{2} \mathrm{Si}\right)$ [51]. The dislocation mechanism is changed to an Orowan mechanism and further ageing will imply a reduction in hardness.

The increasing hardness in Fig. 7 suggests that the methodology was able to avoid a dislocation mechanism transition. Experimental results propose that before dislocation transition, the relation between hardness $(H)$ and ageing time $\left(A_{t}\right)$ follows the linear regression (Fig. 7) described in Eq. (5). Additionally, it may be observed that the experimental hardness values are highly relatable with other studies $[33,39,40]$, suggesting a successful processing of the samples.

$H=72.2+0.04 A_{t}$

\subsection{Vibration analysis - determination of damping ratios}

Fig. 8 shows the damping ratios $(\zeta)$ that were determined during the vibration testing. It is apparent that the solution treatment and the initial phase of artificial ageing are able to enhance the damping capacity of the A356 alloy relatively to its as-cast state. However, as the ageing treatment progresses, there is a decrease in damping capacity. The experimental results suggest that there is a linear function that describes the lowering of the damping ratio $(\zeta)$ as the ageing time $\left(\mathrm{A}_{t}\right)$ progresses, according to Eq. (6).

$\zeta=0.0042-3 \times 10^{-6} A_{t}$

Damping is the ability of a material to dissipate energy under cyclic loading, being closely related with the microstructural internal friction and changed by the material processing. The damping mechanisms are known to be originated by thermoelastic, magnetic, viscous and defect effects. However, due to the presented particular processing characteristics and isothermal (room temperature) testing, only the latter is relevant as an internal friction mechanism. The defect damping is closely related to point (vacancies), line (dislocations), surface (grain boundaries) and bulk (micropores and inclusions) defects [1,52]. Nevertheless, it is known that the internal friction in this particular alloy is regulated by a static hysteresis damping [53] due to dislocation and grain boundary damping $[1,52]$. Hence, it is suggested that the particular origin of the predominant damping mechanisms are related with the dislocation and pinning in (Figs. 9 and 10): (i) grain boundaries between $\alpha$-Al $/ \alpha-\mathrm{Al}, \alpha$-Al/eutectic Si, $\alpha-\mathrm{Al} / \beta-\mathrm{Al}_{5} \mathrm{Fe}_{2} \mathrm{Si}$ and $\alpha-\mathrm{Al} / \pi$ $\mathrm{Al}_{8} \mathrm{FeMg}_{3} \mathrm{Si}_{6}$ pairs; (ii) interactions between dissolved $\mathrm{Mg}$, Si and $\alpha$-Al in pre-aged states (solution hardening) and $\alpha-\mathrm{Al} /\left\{\beta^{\prime \prime}, \beta^{\prime}, \beta\left(\mathrm{Mg}_{2} \mathrm{Si}\right)\right\}$ in aged states (precipitation hardening).

Fig. 9 represents a schematic evolution of the microstructure during solution treatment. Initially, the fundamental constituents of the microstructure are $\alpha$-Al grains (with small quantities of dissolved $\mathrm{Mg}$ and $\mathrm{Si}$ ), eutectic $\mathrm{Si}$ and secondary phases (needle-shaped $\beta-\mathrm{Al}_{5} \mathrm{Fe}_{2} \mathrm{Si}, \mathrm{Mg}_{2} \mathrm{Si}$ and script-shaped $\pi-\mathrm{Al}_{8} \mathrm{FeMg}_{3} \mathrm{Si}_{6}-$ Fig. 6). During the solution treatment, the eutectic $\mathrm{Si}$ is transformed to a spheroidized morphology, migrating and changing the interface balance. It is know that $\mathrm{Si} \mathrm{mi-}$ gration from the dendrite arms results in the formation of particle-free zones [47] and changes the eutectic Si shape/size. This implies a decrease in the grain boundary pinning effect and an elevation in internal friction due to boundary sliding $[44,52]$. Schoek $[54,55]$ showed that a spheroid inclusion with a radius $\left(\mathrm{a}_{\mathrm{i}}\right)$ in a matrix of volume $(\mathrm{V})$ with a determined Poisson's ratio $(v)$, generates an inverse quality factor $\left(Q^{-1}\right)$ by interface relaxation and anelastic strain when a shear stress $\left(p_{13}\right)$ in its respective component $\left(\bar{p}_{13}\right)$ is applied (Eq. (7)). Thus, it is suggested that an overall increase in eutectic Si diameter (Fig. 5) generates an increase in the interface damping. 

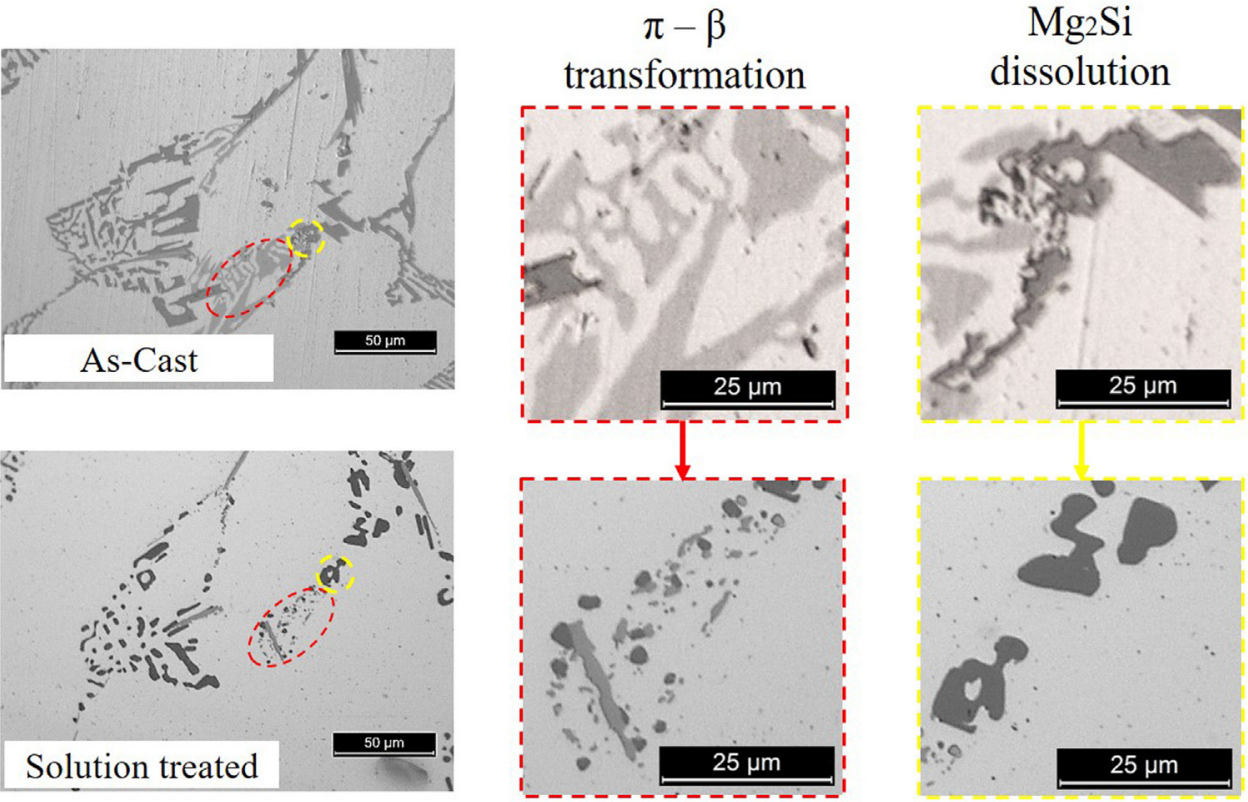

Fig. 6. Eutectic Si and secondary phase morphology change due to solution treatment.

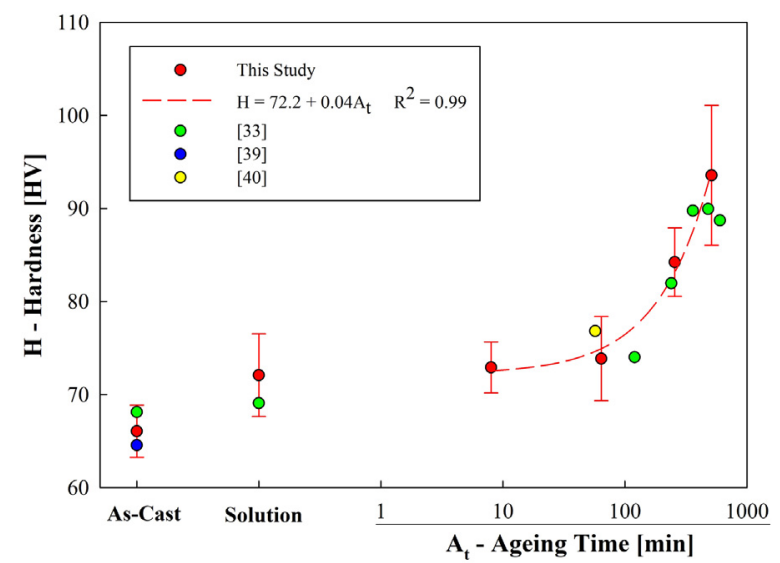

Fig. 7. Hardness of the samples for different heat treatments.

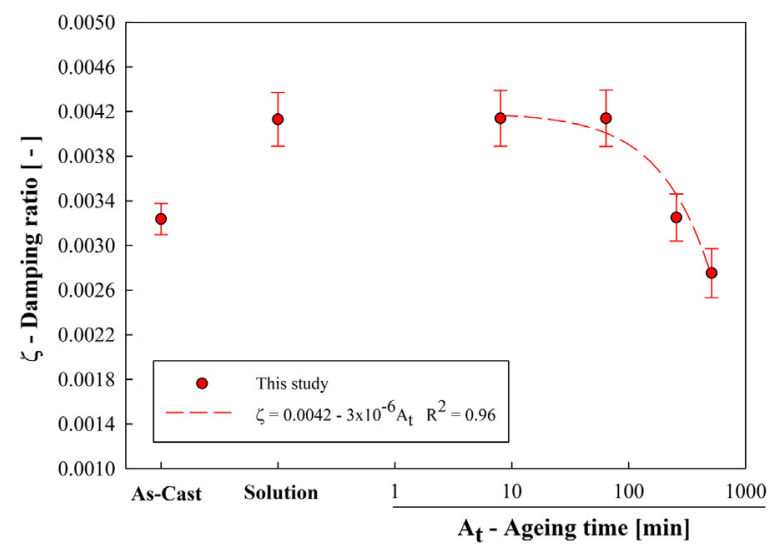

Fig. 8. Damping ratios for different heat treatments.

$Q^{-1}=\frac{1}{{p_{13}}^{2}} \frac{8(1-v)}{3 \pi(2-v)} \frac{1}{V} \sum a_{1}^{3}\left({\overline{p_{13}}}^{2}\right)_{i}$

During solution, however, there is also dissolution of $\mathrm{Mg}_{2} \mathrm{Si}$ in the form of $\mathrm{Mg}$ and $\mathrm{Si}$ elements in the $\alpha$-Al. Additionally, there is further

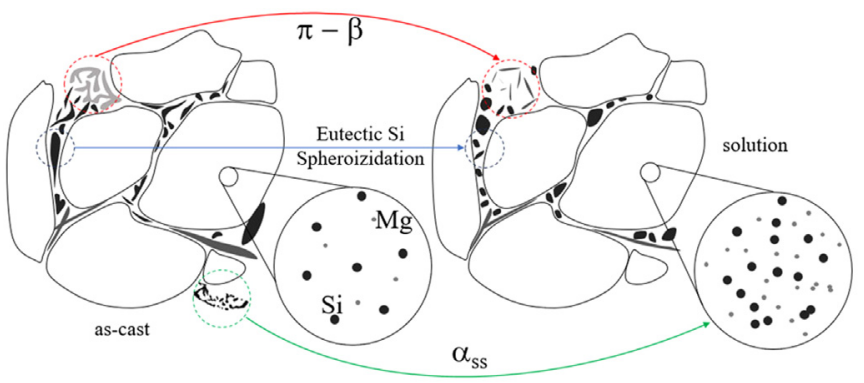

Fig. 9. Damping changes due to microstructural transformation during solution treatment.

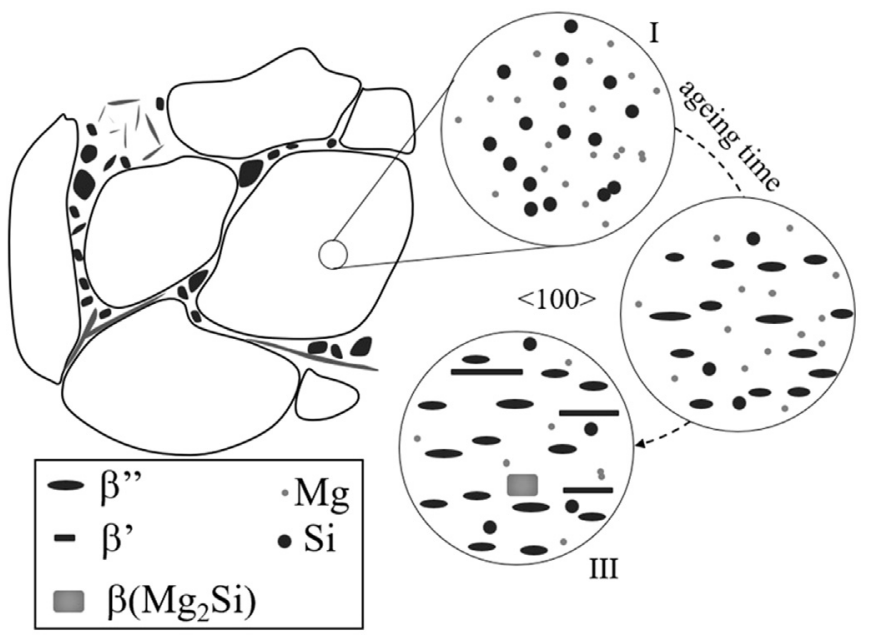

Fig. 10. Damping changes due to microstructural transformation during ageing treatment.

migration of $\mathrm{Mg}$ atoms due to the dissolution of the $\pi-\mathrm{Al}_{8} \mathrm{FeMg}_{3} \mathrm{Si}_{6}$ phase into fine needle shape $\beta-\mathrm{Al}_{5} \mathrm{Fe}_{2} \mathrm{Si}[49,56]$ (Figs. 6 and 9). This supersaturation of $\alpha$-Al enhances pinning and reduces the overall dislocations by solution hardening [51], as it may be observed by the hardness increase in Fig. 7. However, due to the scattered dispersions of 
the atoms, there is no significant reducing in the overall solution treated system damping. Consequently, it may be determined that after solution treatment the maximum value of damping is reached and the most relevant damping mechanism is proportioned by the interface interaction.

Fig. 10 represents the overall microstructural deformation in A356 alloys during ageing treatment. As the intermetallic compounds, eutectic $\mathrm{Si}$ and grain boundaries remain stable due to the relatively low artificial ageing temperatures, it is suggested that the damping is changed due to precipitation hardening. Alloy hardening until peak-age promotes the inhibition of dislocations, being this shown by the increase of hardness values in Fig. 7.

Phase I in Fig. 10 represents an initial stage of ageing treatment, where the overall energy levels are not enough to cluster $\mathrm{Mg}$ and $\mathrm{Si}$ atoms and form GP zones. Studies suggest that GP zones are initially formed after $40 \mathrm{~min}$ of ageing treatment [57]. This hypotheses is in accordance with the experimental values of hardness (Fig. 7) and damping ratio (Fig. 8) for low ageing times. As the ageing treatment progresses, clusters of $\mathrm{Si}$ and $\mathrm{Mg}$ atoms cluster into GP zones, initiating phase II (Fig. 10), where the metastable coherent $\beta$ " nucleate and grow in the dislocation lines with $\mathrm{a}<100>$ direction. There is an increase in pinning points and a reduction of the overall distance between them, being the dislocation mechanism governed by shearing [58]. According to the Granato-Lücke theory [59], the strain independent internal friction $\left(\delta_{0}\right)$ is proportional to the dislocation density $(\rho)$ and the mean length between weak pinning points $\left(\mathrm{L}_{\mathrm{d}}\right)$ (Eq. (8)) [60]. The independent strain amplitude approach is applied in this study due to low stresses ( $\sigma_{\text {Máx }} \sim 30 \mathrm{MPa}$, by classic Timoshenko beam theory) generated by the hammer impact.

$\delta_{0} \sim \rho L_{d}^{4}$

Therefore, it is suggested that the precipitation of $\beta$ " metastable phases is able to lower the damping by the obstruction of dislocation. This hypotheses is supported by the progressive hardness increase during the ageing treatment (Fig. 7). As the nucleation and growth of metastable $\beta$ " increases its volume fraction the precipitation hardness tends to peak-age [26]. However, some semi-coherent $\beta^{\prime}$ and equilibrium $\beta\left(\mathrm{Mg}_{2} \mathrm{Si}\right)$ may simultaneously precipitate from $\beta$ " (phase III Fig. 10). The nucleation processes between metastable precipitates are not exclusive and, thus, there is concurrent growth between the metaand stable-phases [27]. Due to this effect the experimental damping values tend to a minimum, being lower than as-cast-samples (Fig. 8).

\subsection{Tensile testing - determination of yield strength}

Fig. 11 shows the yield strength $\left(\sigma_{Y}\right)$ of as-cast, solution treated and different artificial aged samples. It may be observed that the solution treatment was able to fairly elevate the alloy yield strength, while the

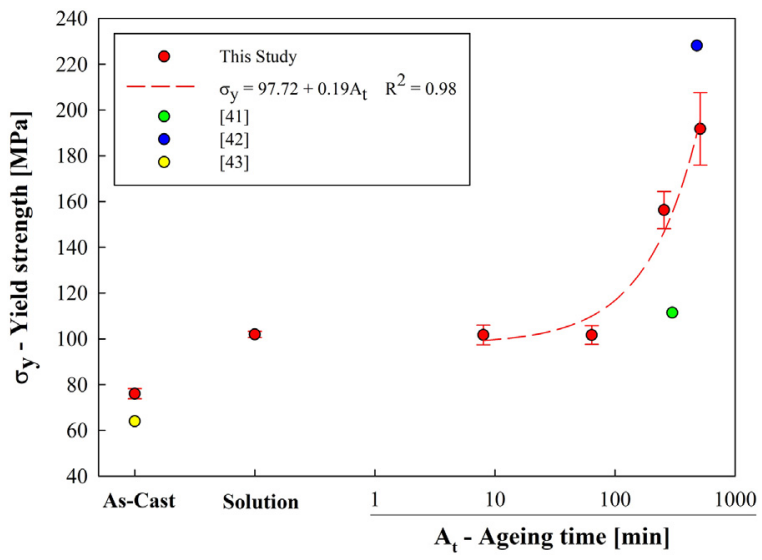

Fig. 11. Yield strength for different heat treatments. artificial ageing treatment has a very pronounced effect in the enhancement of this variable. According to the experimental results, it is suggested that the dependence between yield strength and ageing time for A356 alloy poured in ceramic block follows the linear function described by Eq. (9). Additionally, it may be noticed that this data is fairly correlated and follows the tendency of other published experimental results on the same alloy [41-43].

$\sigma_{Y}=97.72+0.19 A_{t}$

The yield strength $\left(\sigma_{Y}\right)$ of Al-Si-Mg (e.g. A356) alloys may be expressed as an addition of solid solution $\left(\sigma_{S S}\right)$ and precipitation $\left(\sigma_{P P T}\right)$ strengthening components to an initial pure aluminum strength $\left(\sigma_{i}\right)$, as shown in Eq. (10) [61].

$\sigma_{Y}=\sigma_{i}+\sigma_{S S}+\sigma_{P P T}$

The solution strengthening term $\left(\sigma_{S S}\right)$ is dependent on the alloy intrinsic solid solution strength $\left(\sigma_{O S S}\right)$, proportion of solute released $(\alpha)$ and relative volume fraction of precipitates $\left(\mathrm{f}_{\mathrm{r}}\right)$ (Eq. (11)) [61]. The $\sigma_{\text {oss }}$ term includes the influence of eutectic Si and intermetallics, thus, the overall solution strengthening $\left(\sigma_{S S}\right)$ is increased by solution treatment since: (i) Si spheroidization increases yield strength [14,22]; (ii) $\pi-\beta$ transformation is beneficial to reduce microstructural stress concentration [50]; and (iii) precipitation is residual $\left(f_{\mathrm{r}} \sim 0\right)$ during solution treatment [51]. This increase in yield strength by solution strengthening is observed in the experimental results of Fig. 11.

$\sigma_{S S}=\sigma_{0 S S}\left(1-\alpha f_{r}\right)^{\frac{2}{3}}$

According to the same relation (Eq. (11)), due to the nucleation and growth of precipitates during artificial ageing and no variation in $\sigma_{\text {oss }}$, the solution strengthening may decrease. However, this effect has a relatively small role when compared with the increase in aged samples precipitation strengthening [61] as shown by the experimental results.

Precipitation strengthening ( $\sigma_{P P T}-$ Eq. (12)) before peak-age is fundamentally dependent on the volume fraction of precipitates $\left(f_{r}\right)$ and mean precipitate radius $(r)$, for $r$ smaller than the transition radius $\left(r_{\text {trans }}\right)$. The constant $c_{1}$ is related to the Taylor factor, Burgers vector, precipitate shear modulus and interfacial energy [61].

$\sigma_{P P T}=c_{1} f_{r}^{\frac{1}{2}}\langle r\rangle^{\frac{1}{2}} \rightarrow\langle r\rangle<r_{\text {trans }}$

As the ageing time progresses, GP zones $(\mathrm{r}<2 \mathrm{~nm}[25,61])$ followed by $\beta$ " $(2<\mathrm{r}<7 \mathrm{~nm}$ [61]) precipitates, are nucleated and grown (Fig. 10 - phase I to II). This increases the mean precipitate radius ( $\mathrm{r}$ ) and the overall yield strength $\left(\sigma_{Y}\right)$ (Eq. (12)). Some $\beta$, $(7<\mathrm{r}<15 \mathrm{~nm}[24,61])$ and $\beta\left(\mathrm{Mg}_{2} \mathrm{Si}\right)(15<\mathrm{r}<500 \mathrm{~nm}[61,62])$ with $\mathrm{r}$ larger than $\mathrm{r}_{\text {trans }}$ may also nucleate (i.e. lowering $\sigma_{P P T}$ by Orowan dislocation - phase II in Fig. 10). However, their presence is residual before peak-age and does not contribute significantly to the mean radius ( $<\mathrm{r}>$ ) value. Overall, the experimental results (Fig. 11) show the described transformations and, consequently, an enhancement of yield strength by precipitation strengthening.

\subsection{Tailoring of yield/damping mechanical properties in A356 alloys}

The microstructural changes in A356 alloys during ageing treatment (Section 3.1) generate the inverse proportionality between the experimental damping ratio (Section 3.2) and yield strength (Section 3.3) shown in Fig. 12. Under-aged samples (8-64 min ageing times) present similar damping ratios and yield strengths. However, as the ageing time increases, the damping ratios tend to decrease as the yield strength increases on a linear function relation. It is suggested, from a mechanical design point-of-view, that these variables may be dependently tailored by ageing treatment, employing the relation established in Eq. (13).

$\sigma_{y}=367.2-64.2 \times 10^{3} \zeta$ 


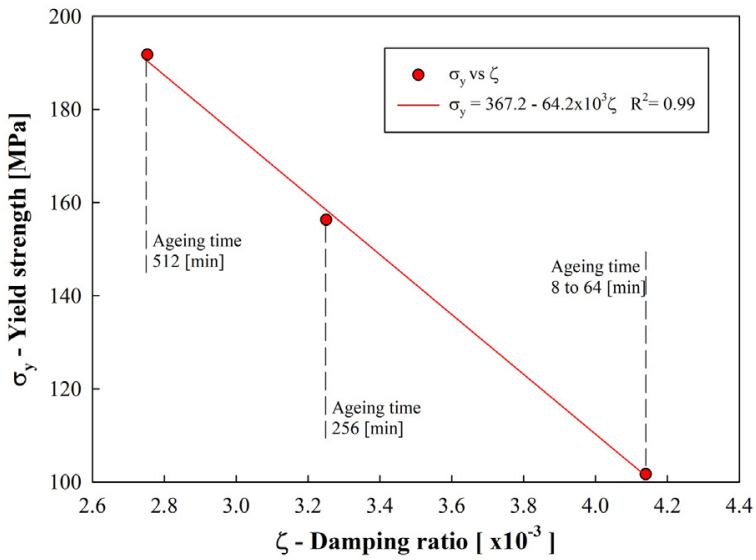

Fig. 12. Proposed model for yield strength and damping ratio dependence.

\section{Conclusion}

The present study explores the influence of the ageing treatment in the overall microstructural morphology and its transformation in the damping ratio and yield strength of A356 alloy poured in ceramic block. According to the results, a dependence between yield strength (static behavior) and damping (dynamic behavior) is analyzed, and the following conclusions are drawn:

(i) Solution treatment is able to enhance both yield strength and damping ratio. Damping is raised to a maximum value due to the increase in grain boundary dislocation promoted by eutectic $\mathrm{Si}$ spheroidization. The increase in yield strength is stimulated by eutectic Si spheroidization/agglomeration, lowering of stress concentration by $\pi-\beta$ intermetallic transformation and solution strengthening due to $\mathrm{Mg}$ and Si dissolution in the $\alpha$-Al.

(ii) Artificial ageing generates a decrease in damping, however, it is able to significantly elevate the yield strength until peak-age. Precipitation hardening, by the nucleation of GP zones and later by the precipitation and increase in volume fraction of $\beta$ ", reduces the lengths between pinning points and dislocations as ageing time progresses. This dislocation reduction is able to successfully elevate the yield strength.

(iii) During artificial ageing, the elevation in yield strength is inversely proportional to the decrease in the damping ratio. It is suggested that this relation follows a linear tendency. The formulated function is a useful tool in the structural/mechanical design when both static and dynamic characteristics must be evaluated.

\section{Acknowledgements}

This research was supported by the project iRAIL Innovation in Railway Systems and Technologies Doctoral Programme funds and by national funds through FCT - Portuguese Foundation for Science and Technology and was developed on the aim of the Doctoral grant PD/ BD/114096/2015.

\section{Data availability}

The raw/processed data required to reproduce these findings cannot be shared at this time as the data also forms part of an ongoing study.

\section{References}

[1] Y. Zhang, N. Ma, Y. Le, S. Li, H. Wang, Mechanical properties and damping capacity after grain refinement in A356 alloy, Mater. Lett. 59 (2005) 2174-2177, http://dx. doi.org/10.1016/j.matlet.2005.02.058.

[2] W. Jiang, Z. Fan, D. Liu, D. Liao, X. Dong, X. Zong, Correlation of microstructure with mechanical properties and fracture behavior of A356-T6 aluminum alloy fabricated by expendable pattern shell casting with vacuum and low-pressure, gravity casting and lost foam casting, Mater. Sci. Eng. A. 560 (2013) 396-403, http://dx.doi.org/10.1016/j.msea.2012.09.084.

[3] B. Milkereit, H. Fröck, C. Schick, O. Kesselr, Continuous cooling precipitation diagram of cast aluminium alloy Al-7Si-0.3Mg, Trans. Nonferrous Met. Soc. China 24 (2014) 2025-2033, http://dx.doi.org/10.1016/S1003-6326(14)63308-2.

[4] H. Puga, J. Barbosa, T. Azevedo, S. Ribeiro, J.L. Alves, Low pressure sand casting of ultrasonically degassed AlSi7Mg0.3 alloy: modelling and experimental validation of mould filling, Mater. Des. 94 (2016) 384-391, http://dx.doi.org/10.1016/j.matdes. 2016.01.059.

[5] A. Kolahdooz, S. Aminian, Effects of important parameters in the production of AlA356 alloy by semi-solid forming process, J. Mater. Res. Technol. (2018), http://dx. doi.org/10.1016/j.jmrt.2017.11.005.

[6] K. Tsuyoshi-Takahashi, Sasaki, Low cycle thermal fatigue of aluminum alloy cylinder head in consideration of changing metrology microstructure, Fatigue 2 (2010) 767-776, http://dx.doi.org/10.1016/j.proeng.2010.03.083.

[7] M. Tebaldini, C. Petrogalli, G. Donzella, G.M. La Vecchia, Estimation of Fatigue Limit of a A356-T6 Automotive Wheel in Presence of Defects, in: Proceedings of the 3rd Int. Symp. Fatigue Des. Mater. Defects FDMD 2017. 7 (2017) 521-529. 〈http:// dx.doi.org/10.1016/j.prostr.2017.11.121>.

[8] Y. Xuan, L. Nastac, The role of ultrasonic cavitation in refining the microstructure of aluminum based nanocomposites during the solidification process, Ultrason. Adv, Appl. Mater. Sci. 83 (2018) 94-102, http://dx.doi.org/10.1016/j.ultras.2017.06. 023.

[9] H. Puga, V.H. Carneiro, C. Jesus, J. Pereira, V. Lopes, Influence of particle diameter in mechanical performance of $\mathrm{Al}$ expanded clay syntactic foams, Compos. Struct. 184 (2018) 698-703, http://dx.doi.org/10.1016/j.compstruct.2017.10.040.

[10] Z. Liu, N. Cheng, Q. Zheng, J. Wu, Q. Han, Z. Huang, J. Xing, Y. Li, Y. Gao, Processing and tensile properties of A356 composites containing in situ small-sized Al3Ti particulates, Mater. Sci. Eng. A 710 (2018) 392-399, http://dx.doi.org/10. 1016/j.msea.2017.11.005.

[11] H. Lee, S.S. Sohn, C. Jeon, I. Jo, S.-K. Lee, S. Lee, Dynamic compressive deformation behavior of SiC-particulate-reinforced A356 Al alloy matrix composites fabricated by liquid pressing process, Mater. Sci. Eng. A 680 (2017) 368-377, http://dx.doi. org/10.1016/j.msea.2016.10.102.

[12] Y. Birol, Impact of grain size on mechanical properties of AlSi7Mg0.3 alloy, Mater. Sci. Eng. A 559 (2013) 394-400, http://dx.doi.org/10.1016/j.msea.2012.08.115.

[13] A. Mehmood, M. Shah, N.A. Sheikh, J.A. Qayyum, S. Khushnood, Grain refinement of ASTM A356 aluminum alloy using sloping plate process through gravity die casting, Alex. Eng. J. 55 (2016) 2431-2438, http://dx.doi.org/10.1016/j.aej.2016. 03.016.

[14] E. Ogris, A. Wahlen, H. Lüchinger, P. Uggowitzer, On the silicon spheroidization in Al-Si alloys, J. Light Met. 2 (2002) 263-269, http://dx.doi.org/10.1016/S14715317(03)00010-5.

[15] P. Wang, H. Lu, Y. Lai, Control of silicon solidification and the impurities from an Al-Si melt, J. Cryst. Growth 390 (2014) 96-100, http://dx.doi.org/10.1016/j. jcrysgro.2013.12.024.

[16] S. Wang, R. Ma, Y. Wang, Y. Wang, L. Yang, Growth mechanism of primary silicon in cast hypoeutectic Al-Si alloys, Trans. Nonferrous Met. Soc. China 22 (2012) 1264-1269, http://dx.doi.org/10.1016/S1003-6326(11)61314-9.

[17] B. Dang, Y.B. Li, F. Liu, Q. Zuo, M.C. Liu, Effect of T4 heat treatment on microstructure and hardness of A356 alloy refined by $\mathrm{Ga}+\mathrm{In}+\mathrm{Sn}$ mixed alloy, Mater. Des. 57 (2014) 73-78, http://dx.doi.org/10.1016/j.matdes.2013.12.022.

[18] J.A. Taylor, Iron-Containing Intermetallic Phases in Al-Si Based Casting Alloys, in: Proceedings of the 11th Int. Congr. Metall. Mater. SAMCONAMET 2011. 1 (2012) 19-33. 〈http://dx.doi.org/10.1016/j.mspro.2012.06.004〉.

[19] T. Tunçay, S. Bayoğlu, The effect of iron content on microstructure and mechanical properties of A356 cast alloy, Metall. Mater. Trans. B 48 (2017) 794-804, http://dx. doi.org/10.1007/s11663-016-0909-1.

[20] S. Ji, W. Yang, F. Gao, D. Watson, Z. Fan, Effect of iron on the microstructure and mechanical property of $\mathrm{Al}-\mathrm{Mg}-\mathrm{Si}-\mathrm{Mn}$ and $\mathrm{Al}-\mathrm{Mg}-\mathrm{Si}$ diecast alloys, Mater. Sci. Eng. A 564 (2013) 130-139, http://dx.doi.org/10.1016/j.msea.2012.11.095.

[21] M. Sacinti, E. Cubuklusu, Y. Birol, Effect of iron on microstructure and mechanical properties of primary AlSi7Mg0.3 alloy, Int. J. Cast. Met. Res. 30 (2017) 96-102, http://dx.doi.org/10.1080/13640461.2016.1250035.

[22] C. Yang, Y. Li, B. Dang, H. Lü, F. Liu, Effects of cooling rate on solution heat treatment of as-cast A356 alloy, Trans. Nonferrous Met. Soc. China 25 (2015) 3189-3196, http://dx.doi.org/10.1016/S1003-6326(15)63952-8.

[23] H.C. Long, J.H. Chen, C.H. Liu, D.Z. Li, Y.Y. Li, The negative effect of solution treatment on the age hardening of A356 alloy, Mater. Sci. Eng. A 566 (2013) 112-118, http://dx.doi.org/10.1016/j.msea.2012.12.093.

[24] G.Y. Liu, Effect of Ageing Heat Treatment on the Hardness and Tensile Properties of Aluminum A356. 2 Casting Alloy, 2009.

[25] H.K. Småbråten, Characterization of precipitates at maximum hardness and overaged conditions in Al-Mg-Si alloys, 2011.

[26] Y. Ohmori, L.C. Doan, K. Nakai, Ageing processes in Al-Mg-Si alloys during continuous heating, Mater. Trans. 43 (2002) 246-255.

[27] C.-S. Tsao, C.-Y. Chen, U.-S. Jeng, T.-Y. Kuo, Precipitation kinetics and transformation of metastable phases in Al-Mg-Si alloys, Acta Mater. 54 (2006) 4621-4631, http://dx.doi.org/10.1016/j.actamat.2006.06.005.

[28] K. Buchanan, K. Colas, J. Ribis, A. Lopez, J. Garnier, Analysis of the metastable precipitates in peak-hardness aged $\mathrm{Al}-\mathrm{Mg}-\mathrm{Si}(-\mathrm{Cu})$ alloys with differing Si contents, Acta Mater. 132 (2017) 209-221, http://dx.doi.org/10.1016/j.actamat.2017.04. 037.

[29] M. Johnsson, L. Backerud, G.K. Sigworth, Study of the mechanism of grain 
refinement of aluminum after additions of Ti- and B-containing master alloys, Metall. Trans. A 24 (1993) 481-491, http://dx.doi.org/10.1007/BF02657335.

[30] A.M. Samuel, H.W. Doty, S. Valtierra, F.H. Samuel, New method of eutectic silicon modification in cast Al-Si alloys, Int. J. Met. 11 (2017) 475-493, http://dx.doi.org/ 10.1007/s40962-016-0089-4.

[31] Y. Birol, Melt treatment of Al-Si foundry alloys with B and Sr additions, J. Mater. Sci. 52 (2017) 6856-6865, http://dx.doi.org/10.1007/s10853-017-0923-y.

[32] Z. Lu, L. Zhang, Thermodynamic description of the quaternary Al-Si-Mg-Sc system and its application to the design of novel Sc-additional A356 alloys, Mater. Des. 116 (2017) 427-437, http://dx.doi.org/10.1016/j.matdes.2016.12.034.

[33] S.L. Pramod, Ravikirana, A.K.P. Rao, B.S. Murty, S.R. Bakshi, Effect of Sc addition and T6 aging treatment on the microstructure modification and mechanical properties of A356 alloy, Mater. Sci. Eng. A 674 (2016) 438-450, http://dx.doi.org/10. 1016/j.msea.2016.08.022.

[34] J.Y. Wang, B.J. Wang, L.F. Huang, Structural evolution of Al-8\%Si hypoeutectic alloy by ultrasonic processing, J. Mater. Sci. Technol. 33 (2017) 1235-1239, http:// dx.doi.org/10.1016/j.jmst.2017.07.018.

[35] J. Barbosa, H. Puga, Ultrasonic melt processing in the low pressure investment casting of Al alloys, J. Mater. Process. Technol. 244 (2017) 150-156, http://dx.doi. org/10.1016/j.jmatprotec.2017.01.031.

[36] I. Narasimha Murthy, N. Arun Babu, J. Babu Rao, Microstructure and Mechanical properties of A356 alloy Castings made in Sand and Granulated Blast Furnace Slag Moulds, in: Proceedings of the International Conference Process. Mater. Miner. Energy July 29th - 30th 2016 Ongole Andhra Pradesh India. 5 161-167. doi:10. 1016/j.matpr.2017.11.067, 2018.

[37] W. Jiang, Z. Fan, X. Chen, B. Wang, H. Wu, Combined effects of mechanical vibration and wall thickness on microstructure and mechanical properties of A356 aluminum alloy produced by expendable pattern shell casting, Mater. Sci. Eng. A 619 (2014) 228-237, http://dx.doi.org/10.1016/j.msea.2014.09.102.

[38] R.J. Immanuel, S.K. Panigrahi, Deformation behavior of ultrafine grained A356 material processed by cryorolling and development of Johnson-Cook model, Mater. Sci. Eng. A 712 (2018) 747-756, http://dx.doi.org/10.1016/j.msea.2017.12.015.

[39] S.A. Kori, M.S. Prabhudev, T.M. Chandrashekharaiah, Studies on the microstructure and mechanical properties of A356 alloy with minor additions of copper and magnesium, Trans. Indian Inst. Met. 62 (2009) 353-356, http://dx.doi.org/10. 1007/s12666-009-0052-7.

[40] B. Dang, C. Liu, F. Liu, Y. Liu, Y. Li, Effect of as-solidified microstructure on subsequent solution-treatment process for A356 Al alloy, Trans. Nonferrous Met. Soc. China 26 (2016) 634-642, http://dx.doi.org/10.1016/S1003-6326(16)64152-3.

[41] L. Liu, F. Samuel, Effect of inclusions on the tensile properties of $\mathrm{Al}-7 \% \mathrm{Si}-0.35 \%$ Mg (A356.2) aluminium casting alloy, J. Mater. Sci. 33 (1998) 2269-2281, http:// dx.doi.org/10.1023/A:1004331219406.

[42] P. Li, S. Liu, L. Zhang, X. Liu, Grain refinement of A356 alloy by Al-Ti-B-C master alloy and its effect on mechanical properties, Mater. Des. 47 (2013) 522-528, http://dx.doi.org/10.1016/j.matdes.2012.12.033.

[43] E.I. Bhiftime, N.F.D.S. Gueterres, Investigation on the mechanical properties of A356 Alloy reinforced AlTiB/SiC p composite by semi-solid stir casting method, IOP Conf. Ser. Mater. Sci. Eng. 202 (2017) 12081.

[44] Y. Zhang, N. Ma, H. Wang, X. Li, Study on damping behavior of A356 alloy after grain refinement, Mater. Des. 29 (2008) 706-708, http://dx.doi.org/10.1016/j. matdes.2007.03.002.

[45] C.M. Dinnis, A.K. Dahle, J.A. Taylor, M.O. Otte, The influence of strontium on porosity formation in Al-Si alloys, Metall. Mater. Trans. A 35 (2004) 3531-3541, http://dx.doi.org/10.1007/s11661-004-0190-9.

[46] K. Nogita, A.K. Dahle, Mechanism of porosity formation and eutectic modification in hypoeutectic Al-Si alloys, J. Jpn. Inst. Light Met. 54 (2004) 440-446, http://dx. doi.org/10.2464/jilm.54.440.

[47] R. Chen, Q. Xu, Z. Jia, B. Liu, Precipitation behavior and hardening effects of Sicontaining dispersoids in Al-7Si-Mg alloy during solution treatment, Mater. Des. 90 (2016) 1059-1068, http://dx.doi.org/10.1016/j.matdes.2015.11.069.

[48] J. Davids, ASM Specialty Handbook, Aluminium and Aluminum Alloys, (1993).

[49] J.Y. Yao, J.A. Taylor, Characterisation of intermetallic particles formed during solution treatment of an Al-7Si-0.4Mg-0.12Fe alloy, J. Alloy. Compd. 519 (2012) 60-66, http://dx.doi.org/10.1016/j.jallcom.2011.12.047.

[50] X. Cao, J. Campbell, Morphology of $\beta$-Al5FeSi phase in Al-Si cast alloys, Mater. Trans. 47 (2006) 1303-1312.

[51] A. Bahrami, Modeling of Precipitation Sequence and Ageing Kinetics in Al-Mg-Si Alloys, 2010.

[52] J. Zhang, R.J. Perez, C.R. Wong, E.J. Lavernia, Effects of secondary phases on the damping behaviour of metals, alloys and metal matrix composites, Mater. Sci. Eng. R Rep. 13 (1994) 325-389, http://dx.doi.org/10.1016/0927-796X(94)90010-8.

[53] J. Zhang, R.J. Perez, E.J. Lavernia, Documentation of damping capacity of metallic, ceramic and metal-matrix composite materials, J. Mater. Sci. 28 (1993) 2395-2404, http://dx.doi.org/10.1007/BF01151671.

[54] G. Schoeck, Internal friction due to precipitation, Phys. Status Solidi B 32 (1969) 651-658.

[55] G. Schoeck, E. Bisogni, Internal Friction in Al $\square$ Ag Alloys, Phys. Status Solidi B 32 (1969) 31-40.

[56] J.A. Taylor, D.H. StJohn, J. Barresi, M.J. Couper, Influence of Mg content on the microstructure and solid solution chemistry of Al-7\% Si-Mg casting alloys during solution treatment, Trans. Tech. Publ. (2000) 277-282.

[57] S. Liu, K. Li, J. Lu, G. Sha, J. Wang, M. Yang, G. Ji, M. Song, J. Wang, Y. Du, On the atomic model of Guinier-Preston zones in Al-Mg-Si-Cu alloys, J. Alloy. Compd. (2018), http://dx.doi.org/10.1016/j.jallcom.2018.01.304.

[58] G. Guo, Q. Wang, G. Wang, Y. Rong, A Brief Review of Precipitation Hardening Models for Aluminum Alloys, in: Proceedings of the 2nd World Congr. Integr. Comput. Mater. Eng., John Wiley \& Sons, Inc., 2013: pp. 249-254. 〈http://dx.doi. org/10.1002/9781118767061.ch40>.

[59] A. v. Granato, K. Lücke, Theory of mechanical damping due to dislocations, J. Appl. Phys. 27 (1956) 583-593.

[60] H. Puga, V.H. Carneiro, J. Barbosa, D. Soares, Effect of grain and secondary phase morphologies in the mechanical and damping behavior of Al7075 alloys, Met. Mater. Int. 22 (2016) 863-871, http://dx.doi.org/10.1007/s12540-016-6073-y.

[61] L.J. Colley, M.A. Wells, W.J. Poole, Microstructure-yield strength models for heat treatment of $\mathrm{Al}-\mathrm{Si}-\mathrm{Mg}$ casting alloys II: modelling microstructure and yield strength evolution, Can. Metall. Q. 53 (2014) 138-150, http://dx.doi.org/10.1179/ 1879139513 Y.0000000111.

[62] G. Ran, J.E. Zhou, Q.G. Wang, Precipitates and tensile fracture mechanism in a sand cast A356 aluminum alloy, J. Mater. Process. Technol. 207 (2008) 46-52, http://dx. doi.org/10.1016/j.jmatprotec.2007.12.050. 